Research Paper

\title{
The Effect of Violent and Melodrama Movies on Risky Decision-making and Behavioral Inhibition in Adolescents
}

\author{
Roya Ghandali' ${ }^{1,2}$ (D), Peyman Hassani-Abharian ${ }^{13^{*}}$ (D), Vahid Sadeghi-Firoozabadi ${ }^{4}$ (D), Roghieh Nooripour ${ }^{5}$ (i)
}

1. Department of Cognitive Rehabilitation, Institute for Cognitive Science Studies, Tehran, Iran

2. Islamic Republic of Iran Broadcasting Research Center, Tehran, Iran.

3. Brain and Cognition Clinic, Institute for Cognitive Science Studies, Tehran, Iran.

4. Department of Psychology, Faculty of Psychology and Education, Shahid Beheshti University, Tehran, Iran.

5. Department of Counseling, Faculty of Education and Psychology, Alzahra University, Tehran, Iran.

\begin{tabular}{|c|c|}
\hline $\begin{array}{l}\text { Use your device to scan } \\
\text { and read the article online }\end{array}$ & Citation Ghandali, R., Hassani-Abharian, P., Sadeghi-Firoozabadi, V., and Nooripour, R. (2022). The Effect of Vio- \\
\hline 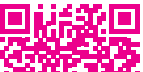 & $\begin{array}{l}\text { lent and Melodrama Movies on Risky Decision-making and Behavioral Inhibition in Adolescents. Basic and Clinical } \\
\text { Neuroscience, 13(6), 765-776. http://dx.doi.org/10.32598/bcn.2021.194.4 }\end{array}$ \\
\hline atsitis & doi http://dx.doi.org/10.32598/bcn.2021.194.4 \\
\hline
\end{tabular}

Article info:

Received: 14 Feb 20218

First Revision: 21 May 2021

Accepted: 24 Aug 2021

Available Online: 01 Nov 2022

Keywords:

Violence, Risk Behavior, Movie, Decision Making, Adolescents

\begin{abstract}
AB S T RAC T
Introduction: Brain functional performance is a collection of outstanding mental processing that provides a framework for achieving goals based on targeted behaviors. Disorders in executive functions make it difficult for a person to perform everyday tasks. One of the phenomena highlighted in various media is the violence that adolescents welcome with the production of violent movies. This study aimed to investigate the effect of violent movies on risky decision-making and behavioral inhibition of adolescents and compare the effects of violence with melodrama movies
\end{abstract}

Methods: This quasi-experimental study was conducted with a pretest-posttest design with a control group among 60 adolescents (30 girls and 30 boys) living in Tehran City, Iran. They were selected using the available sampling method. For this purpose, neurological tests of Iowa Gambling and go-no go were used.

Results: The results showed that violent movies caused a significant increase in risky decision-making $(\mathrm{P}<0.05)$. In addition, these types of movies caused a significant decrease in behavioral inhibition among adolescents $(\mathrm{P}<0.05)$.

Conclusion: Movies with ill-mannered stories and content that glorify violence harm adolescents' decision-making and deterrence, leading them to make risky decisions and weaken their inhibition power.

\footnotetext{
* Corresponding Author:

Peyman Hassani-Abharian, MD, PhD.

Address: Department of Cognitive Rehabilitation, Institute for Cognitive Science Studies, Tehran, Iran.

Tel: +98 (21) 88802063

E-mail: abharian@IRICSS.org; abharian1972@yahoo.com
} 


\section{Highlights}

- Watching violent movies increases the risky decision-making of adolescents significantly.

- Watching violent movies decreases behavioral inhibition control significantly.

- Watching melodrama movies does not increase adolescents' risky decision-making significantly. Watching melodrama videos do not significantly weakenadolescents' inhibition control.

\section{Plain Language Summary}

This present study aimed to investigate the effect of violent movies on risky decision-making and behavioral inhibition in adolescents. Inhibition means the ability to exert control over inappropriate behaviors. The results demonstrate that the more time adolescents spend watching violent movies, the more they are prone to making wrong decisions, such as drug abuse or illegal driving. Moreover, watching a lot of violent movies reduces behavioral inhibition in adolescents. Watching these kinds of movies can adversely affect the cortex, a part of the brain responsible for decision-making and inhibitory behaviors. It also contributes to the increased incidence of risky decision-making and the reduction of suppressing misbehaviors. Movie production companies try to produce films such as thriller movies to attract more viewers. Since the frontal lobe is not fully developed in children and adolescents, they cannot make well-reasoned and rational decisions. They are eager to commit an act of violence and risky behaviors, so they are so interested in watching violent movies. The present study warns parents against selecting movies and recommends that they accompany their children while watching violent movies.

\section{Introduction}

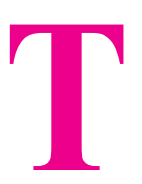

oday, violence is one of the greatest traumas in the world; violence is usually inflicted by a person or persons against themselves (suicide or self-harm) or against others (murder or sadism). Violence has a social nature, mostly rooted in interpersonal and intergroup interactions (Darjee, 2019). It has a negative relationship with appropriate human interaction and social development, and its increase leads to the disruption of human and social relationships and reduces public welfare and community safety (Van Bavel, et al., 2017). Today, with the advent of mass media, especially television, violence is directly broadcasted by human actors and transmitted to others. Now media contributes to the transmission of violence and the emergence of violent behaviors. One type of media violence is TV violence.

The study of TV violence has two concepts: real violence reported in news programs with informational, educational, warning, and alerting roles, and fantasy violence, shown in TV series and movies. The most harmful effect of TV violence is seen among children and adolescents. According to Albert Bandura, this age group cannot understand that violent content should not be imitated (Khurana et al., 2019). The use of violence in TV programs is increasing. The extreme por- trayal of violence in mass media, and especially TV, has led to the transfer of violence from adolescents to adulthood. Without the necessary cognitive, subjective, and social skills, they cannot distinguish between reality and fantasy and are (will be) exposed to various types of violent behaviors (Hu, et al., 2020).

Various studies show that adolescents like TV violence and acts of violent behavior are evident in their behavior (Liu, et al., 2020; Peters et al., 2021). Continuous watching of violent scenes by children and adolescents will reinforce aggressive behavior in this age group, especially since violent behavior in a TV show is not followed by punishment. Adolescents with affective, behavioral, learning, and impulsivity problems are easily affected by TV violence (Zhuang et al., 2021).

Adolescents in the United States watch TV and movies an average of 40 hours per week ( $\mathrm{Li}$, et al., 2020). A comprehensive study in the United States found that $99 \%$ of boys and $94 \%$ of girls play various video games. They found that $70 \%$ of adolescent boys aged 9-18 years prefer violent games and movies.

Rostad, et al. (2021) showed a positive and significant correlation between the hours spent watching television and videos and the violent behavior of those students who devoted significantly more hours to television on weekdays and weekends. 
Some studies have shown that viewing TV pictures of violence increases criminal (Hopf, et al., 2008) or aggressive behaviors (Chang \& Bushman, 2019) in adolescents. There is consistent evidence that violent images in television, film, video, and computer games have significant short-term effects on arousal, thoughts, and emotions and increase the likelihood of aggressive or fearful behavior in younger children, particularly boys (Coyne et al., 2017). A study on more than 2000 second- through eighth-grade students in Ohio in 1998 showed that any increase in hours allocated to daily viewing TV increased the likelihood of symptoms of psychological distress, including anger, depression, and excessive psychological stress (Anderson et al., 2017).

Violent TV programs can have a negative impact on adolescents, including aggressive behavior, the tendency to negative thinking, and the outbreak of anxiety and panic in adolescents, which negatively affect the rest of their lives. However, there are not just effects that violent programs can have (Weegels, 2018). One of the major indicators that should be considered in these studies is the impact on the cognitive functions of the individuals. Several studies conducted in the last half-century have shown that children and adolescents exposed to violent TV programs have lower cognitive functions than children and adolescents not exposed to such programs (Hummer, et al., 2014; Sumner et al., 2015). Executive function is one of the cognitive functions weakened by extreme exposure to violence in television programs. One of these executive functions is attention. Adolescents exposed to violent TV programming have reduced attention, weak working memory, and increased arousal (Lillard, et al., 2015).

The study conducted by Kronenberger et al. (2005) on adolescent groups with and without a diagnosis of psychiatric disorders shows that exposure to TV violence is associated with poor executive functioning. This association is stronger in adolescents with disruptive behavior and attention deficit/hyperactivity disorder. Thus, the results indicate impulsivity, distraction, and attention reduction are more pronounced in individuals with psychiatric disorders.

Media violence exposure (MVE) is associated with aggressive outcomes in adolescents. Using survey data from 1990 adolescents (Mean \pm SD age: $15.6 \pm 1.10$ years) and a content analysis of top American movies and popular shows (TV), we examined the effect of MVE on both risk (i.e., family conflict, impulsivity, sensation-seeking) and protective (i.e., parental moni- toring, parental involvement, parental mediation) factors. Analyses of relative weights showed that MVE was one of the strongest predictors of aggression after impulsivity and family conflict. The cumulative risk score showed linear and quadratic relationships with the likelihood of aggression, with MVE and family conflict having an interactive relationship in predicting aggression. Parental monitoring remained a significant protective factor even when all risk factors were accounted for. Targeted preventive interventions that reduce family conflict, promote parental monitoring, and reduce exposure to violent media may effectively reduce aggressive tendencies and associated negative outcomes (Khurana et al., 2019).

Decision-making and inhibition are the essential components of cognitive and executive functions, which have a crucial role in the selection of gains and losses of the individual and the identification of the desirable from the undesirable decisions. Despite the positive results of the above studies, there is a dearth of research, especially domestic studies, on these two important cognitive functions. On the other hand, the lack of research and study on violent TV or motion pictures and their effects on cognitive functions provides an appropriate opportunity for research in this area. For this reason, we examined the effects of violent media programs on adolescents' risk decisionmaking and behavioral inhibition.

\section{Materials and Methods}

The proposed hypothesis of this study was tested in a quasi-experimental research with a pretest-posttest design and a control group. To measure the two functions of risky decision-making and behavioral inhibition in adolescents aged 11 to 18 years, the Iowa Gambling and the go-no go tasks were administered at the beginning and before the screening of the movie. The violent film and the melodrama film were played for the test group and the control group. Iowa Gambling and the go-no go tasks were repeated for the two groups after watching the movie.

The independent variable of this study is watching violent, and melodrama movies played for 28 minutes and 25 minutes, respectively, for the participants. The dependent variables include the extent of risky decision-making and the participant's insufficiency in behavioral inhibition as measured by the Iowa Gambling and the go-no go tasks. 


\section{Study participants}

The study's statistical population comprised adolescents between 11 and 18 years living in Tehran City, Iran, in 2019. Both girls and boys were studied in this statistical population. The subjects were selected for the study through an available sampling method. The inclusion criteria were the absence of a psychiatric disorder in the participants and the separation or divorce of their parents. Some exclusion criteria were also considered for the study. If the participants or their parents were no longer interested in continuing to collaborate in the study, or it was determined during the study that the participant had a psychiatric disorder, or their parents divorced, we will terminate the collaboration while respecting the participant. The statistical sample size was 60 adolescents, including 60 girls and 60 boys.

\section{Data gathering and questionnaires}

\section{Iowa gambling task}

Iowa gambling task is identical to the "Bechara gambling task". It was called the "Iowa gambling task" because Bechara, Damasio, and Tranel were professors at the University of Iowa when it was invented. The task is used extensively to measure decision-making in risky and unclear situations in various clinical populations. The task is a framework for assessing many disorders in human decision-making. In the $\mathrm{ABCD}$ version of this test used in this study, four groups of 60 cards were placed in front of the subjects. They had a total of 60 choices and were asked to take one card from one of the four categories for each choice. After each choice, they are told the odds of winning or losing. Subjects should try to get the highest net profit on their selection. The cards are divided into winning $(\mathrm{C}, \mathrm{D})$ and losing $(\mathrm{A}, \mathrm{B})$ categories. Although the profitability of the winning cards is low, they are profitable because of the lower losses compared to the wins. The loss cards suggest more profits for the subject than the gain cards; however, they are lossy overall due to the losses compared to the gains. The win rate (for the winning cards) and the loss rate (for the losing cards) increase over time.

Although the average win rate of $\mathrm{A}$ and $\mathrm{B}$ cards is the same, the number of cards in group $A$ that have a chance of losing is higher but lower in each case. Conversely, for Group B cards, the number of cards with a chance of losing is lower, even though the rate of loss for each card is higher. The same is true for the cards in groups $\mathrm{C}$ and $\mathrm{D}$. At the end of the test, the subject's net score is calculated as (A+B) - (C+D) (Mueller, et al., 2010). This task has a main score named the net score. The less the net score of a subject indicates his or her impairment in decision-making. The validity and reliability of this test have been reported to be over $80 \%$ (Fernie \& Tunney, 2006). The validity and reliability of the Persian version of this test is 80\%, too (Ekhtiari, et al., 2017).

\section{Go-no go task}

Hoffman developed this task in 1984. It is often used to assess response inhibition. Response inhibition involves executive control over prepared motor responses by altering the situational demand. In the go-no go task, in one situation (go or motion), the subject is instructed to make a consistent response as quickly as possible when a stimulus appears. In another situation (no go or motion inhibition), another stimulus is provided after the first stimulus, and the subject is instructed to refuse to respond when the second stimulus appears. Two situations of go or no go are randomly assigned to a task. A subject's response in the second situation indicates his inhibitory control. A lack of correct inhibition or a commission error means that a person executes movement responses while presented with nontarget stimuli. This test, administered and measured by computer, gives three different scores: the percentage of commission error, the percentage of incorrect inhibition, and reaction time. The high score in commission error, incorrect inhibition, and reaction time indicates the weakness and inability of the person in reaction inhibition, and the higher the score of the person in these components, the more weakness he has in inhibitory control. In this test, the subject should show a simple movement response (pressing a button) as quickly as possible when the target stimulus (blue square) appears and show no response when the nontarget stimulus (Yellow Square) appears. The validity of the go/no go task was reported to be $87 \%$ (Hosseini, et al., 2012), and its reliability was $80 \%$ (Tabibi, et al., 2015).

\section{Movies}

In this study, two movies were used for the participants, "Saw" and "Gone with the Wind" were the selected movies for this study. "Saw" is an action movie with violent content, and "Gone with the Wind" is a melodrama with emotional content.

\section{Sphygmomanometer (Blood pressure monitor)}

Digital EchoMax Sphygmomanometer model HBP 2000 (made in Korea) was used to measure blood pressure and heart rate. 


\section{Visual Analog Scale}

This scale is a simple, ruler-like scale on which are written the numerals 0 to 100 (ten to ten). Zero indicates the lowest level of violence on this scale, and one hundred indicates the highest level of violence in violent films. This score was also used to evaluate the melodrama films and assess the emotional and affective level of the films from the participant's point of view. Zero indicates the lowest level of affection, and 100 indicates the highest level of affection in melodrama films.

\section{Data analysis}

We used SPSS software, version 24 to analyze the data as mean and standard deviation. The paired t test and the Wilcoxon signed-rank test were used to assess the effect of violent and melodrama movies on the heart rate. A visual check demonstrated that the data were normally distributed.

\section{Results}

The mean age of subjects was 14.57 years with a standard deviation of 24.2 years; the age range was 11 to 18 years. The characteristics of the subjects by gender, age, and education are shown in Table 1. For normal variables, paired samples, parametric $\mathrm{t}$ test, and for nonnormal variables, the Wilcoxon test were used to test the study hypothesis. The dependent variables were risky decision-making, and behavioral inhibition, determined based on the net gain in Iowa gambling task (omission error, commission error) and go/no go task.

The results of the Iowa gambling task after watching the violent and melodrama movies in the pretest-posttest phases using paired $t$ test are shown in Table 2 . The first row shows that the mean score of the participants of the overall rating component is reduced in the posttest of the violent film compared to the pretest of this type of movie. The second row of Table 2 shows that the participants' mean score for the total score component is reduced in the posttest of the melodrama movie compared to the pretest of this movie. The paired $t$ test was used to test the significance of this difference.

As the results of the first row of Table 3 show, there is a significant difference between the mean of the components of the Iowa Gambling Task in the pretest and posttest for a violent movie. This difference is that the mean of the total score component decreased significantly in the pretest and posttest (0.024). Thus, watching a violent movie decreases participants' total score in the posttest compared to the pretest, and adolescents' risky decision-making increases accordingly. The result of the second row of Table 3 shows no significant difference $(\mathrm{P}=0.68)$ between the mean score of the subjects in the total score component in the pretest and posttest in the Iowa gambling task. This difference means that the mean total score for watching a melodrama movie in the pretest and posttest has no significant reduction. Thus, watching melodrama movies did not lead to increased risky decision-making among adolescents.

The results of the go-no go task for two violent and melodrama movies in the pretest and posttest using the Wilcoxon test are shown in Table 4.

As seen in the row about the violent movie in Table 4, the $\mathrm{z}$ scores for commission error, omission error, and behavioral inhibition are $-3.155,-0.258$, and -3.272 , respectively. For commission error, omission error, and behavioral inhibition components, the calculated significance level is less than 0.05 . There is a significant statistical difference between the pretest-posttest scores in the three go-no go task components of the violent movie. In other words, watching a violent movie increases the commission and omission errors and decreases behavioral inhibition. So, the result shows that watching violent movie increases adolescents' shortage in behavioral inhibition (Table 4).

The result of the row on melodrama movies in Table 4 showed that the $\mathrm{z}$ scores for commission error, omission error, and behavioral inhibition are -3.054, -2.496, and -3.522 , respectively. Considering that the values of the calculated significance level in all tests are less than 0.05 , there is a significant statistical difference between the posttest and pretest scores in the three components of the go-no go task. In other words, watching a melodrama movie leads to a significant decrease in commission and omission errors and a significant increase in behavioral inhibition in the posttest phase. Thus, the result shows that watching melodrama movies does not weaken adolescents' behavioral inhibition (Table 4). By comparing the results of violent and melodrama movies in Table 4, it can be concluded that watching violent movies leads to a deficit in inhibition control and the logical response of adolescents. However, watching melodrama movies does not weaken behavioral inhibition. The results of the Wilcoxon test to measure the effect of violent and melodrama movies on systolic and diastolic blood pressure are shown in Table 5. As seen in the row about the violent movie in Table 5 , $\mathrm{z}$ values for systolic and diastolic blood pressure are -1.086 and -2.249 , respectively. Since the calculated significance level for both systolic and diastolic blood 
Table 1. Distribution of respondents by gender, age, and education $(\mathrm{N}=60)$

\begin{tabular}{ccc}
\hline & Variables & No. (\%) \\
\hline Gender & Girl & $30(50)$ \\
& Boy & $30(50)$ \\
Age group (y) & Total & 60(100) \\
& $11-14$ & $26(43.4)$ \\
& $15-18$ & $34(56.6)$ \\
& Total & $60(100)$ \\
Education & Elementary school & $12(18.3)$ \\
& Middle school & $26(45)$ \\
& High school & $26(45)$ \\
& Diploma & $6(10)$ \\
\hline
\end{tabular}

NEURSCIENCE

pressure is less than 0.05 , there is a significant statistical difference between the posttest and pretest values of both types of blood pressure. In other words, watching violent movies affects adolescents' blood pressure and increases systolic and diastolic blood pressure.

The row on melodrama movies in Table 5 also showed that the $\mathrm{z}$ values for systolic and diastolic blood pressure are -0.801 and -2.082 , respectively. Since the calculated significance level for both systolic and diastolic blood pressure is less than 0.05 , there is a significant statistical difference between the posttest and pretest values of both types of blood pressure. In other words, watching melodrama movies increases systolic and diastolic blood pressure. The results of the paired $t$ test measuring the effect of violent and melodrama movies on heart rate are presented in Table 6.

The first row of Table 6 shows that the t value is 0.356 for heart rate while watching a violent movie. Since the calculated significance level $(0.023)$ is less than 0.05 , there is a significant statistical difference between the posttest and pretest values of average heart rate. For this reason, the results of Table 6 suggest that watching vio-

Table 2. Scores of Iowa gambling task in violent and melodrama movies $(\mathrm{N}=60)$

\begin{tabular}{ccc}
\hline \multirow{2}{*}{ Movie Type } & \multicolumn{2}{c}{ Total Score (Mean \pm SD) } \\
\cline { 2 - 3 } & Pretest & Posttest \\
\hline Violent & $28.79 \pm-2.55$ & $25.69 \pm-1.06$ \\
Melodrama & $3.74 \pm 1.03$ & $4.55 \pm 1.13$ \\
\hline
\end{tabular}

NEUR SCIENCE

Table 3. Paired t-test in score of Iowa gambling task in violent and melodrama movies $(\mathrm{N}=60)$

\begin{tabular}{cccccc}
\hline Movie Type & Variable & Mean Differences & $\mathbf{t}$ & df & Sig. \\
\hline Violent & Total score & -4.51 & -2.32 & 59 & 0.024 \\
Melodrama & Total score & 1.40 & 0.40 & 59 & 0.68 \\
\hline
\end{tabular}


Table 4. Wilcoxon test in a score of the components of go-no go task in violent and melodrama movies $(\mathrm{N}=60)$

\begin{tabular}{|c|c|c|c|c|c|c|c|}
\hline \multirow{2}{*}{ Movie Type } & \multirow{2}{*}{ Variable } & \multicolumn{2}{|c|}{ Pre-test } & \multicolumn{2}{|c|}{ Post-test } & \multirow{2}{*}{$\mathbf{Z}$} & \multirow{2}{*}{ Sig. } \\
\hline & & Mean & Rank Set & Mean & Rank Set & & \\
\hline \multirow{3}{*}{ Violent } & Commission error & 19.97 & 639 & 22.63 & 181 & -3.155 & 0.002 \\
\hline & Omission error & 5 & 30 & 6.25 & 25 & -0.258 & 0.047 \\
\hline & Behavioral inhibition & 22.71 & 159 & 19.41 & 621 & -3.272 & 0.001 \\
\hline \multirow{3}{*}{ Melodrama } & Commission error & 19.44 & 525 & 15.67 & 141 & -3.054 & 0.002 \\
\hline & Omission error & 5.56 & 50 & 5 & 5 & -2.496 & 0.013 \\
\hline & Behavioral inhibition & 13.44 & 121 & 20.79 & 582 & -3.522 & 0.000 \\
\hline
\end{tabular}

Table 5. Wilcoxon test to measure the effect of violent and melodrama movies on systolic and diastolic blood pressure ( $\mathrm{N}=60)$

\begin{tabular}{|c|c|c|c|c|c|c|c|}
\hline \multirow{2}{*}{ Movie Type } & \multirow{2}{*}{ Variable } & \multicolumn{2}{|c|}{ Pre-test } & \multicolumn{2}{|c|}{ Post-test } & \multirow{2}{*}{ Z } & \multirow{2}{*}{ Sig. } \\
\hline & & Mean & Rank Set & Mean & Rank Set & & \\
\hline \multirow{2}{*}{ Violent } & Diastolic blood pressure & 16.08 & 209 & 16.79 & 319 & -1.086 & 0.027 \\
\hline & Systolic blood pressure & 20.19 & 323 & 20.71 & 497 & -2.249 & 0.021 \\
\hline \multirow{2}{*}{ Melodrama } & Diastolic blood pressure & 17.64 & 317.5 & 21.19 & 423.5 & -0.801 & 0.023 \\
\hline & Systolic blood pressure & 17.19 & 460.5 & 19.13 & 205.5 & -2.082 & 0,037 \\
\hline
\end{tabular}

NEUR SCIENCE

lent movies increases the heart rate of adolescents. However, the results of the second row of Table 6 show that the $t$ value is -0.828 for heart rate while watching melodrama. Since the calculated significance level $(0.023)$ is greater than 0.05 , there is no significant statistical difference between the posttest and pretest values of average heart rate, so watching melodrama movies does not cause any significant change in heart rate. Watching melodrama movies does not affect heart rate.

\section{Discussion and Conclusion}

This study showed that watching violent movies increased adolescents' risky decision-making. Watching violent movie content also weakens and decreases adolescents' behavioral inhibition power. Furthermore, results showed that watching violent movies increased participants' systolic and diastolic blood pressure and heart rate. However, watching melodrama movies does not significantly increase risky decision-making; it empowers adolescents' behavioral inhibition. Watching melodrama movies also increased systolic and diastolic blood pressure significantly; however, no change was observed in heart rate.

According to the findings of Fikkers, et al. (2017) and Seabrook, et al. (2019), watching violent TV movies had a significant effect on increasing the propensity to vio-

Table 6. Paired $t$ test to measure the effect of violent and melodrama movies on the heart rate $(\mathrm{N}=60)$

\begin{tabular}{|c|c|c|c|c|c|c|c|}
\hline \multirow{2}{*}{ Movie Types } & \multirow{2}{*}{ Variables } & \multicolumn{2}{|c|}{ Pre-test } & \multicolumn{2}{|c|}{ Post-test } & \multirow{2}{*}{$\mathbf{t}$} & \multirow{2}{*}{ Sig. } \\
\hline & & Mean & Rank Set & Mean & Rank Set & & \\
\hline Violent & Heart rate & 86.40 & 13.67 & 86.83 & 14.65 & 0.356 & 0.023 \\
\hline Melodrama & Heart rate & 85.05 & 13.19 & 85.95 & 13.53 & -0.828 & 0.411 \\
\hline
\end{tabular}


lence in children. According to Alia Klein, et al. (2014), viewing violence in the media affected the functions of the orbitofrontal cortex, including decision-making. This means that exposure to media violence decreases the activity of the orbitofrontal cortex, and as a result, decision-making is weakened. Therefore, since the growth trajectory of adolescents is not yet complete emotionally and effectively, exposure to violence and especially media violence, which is usually accompanied by intriguing storytelling, could impair cognitive functions and weaken the development of their organizational performance. This may impair their decisionmaking and jeopardize their alternatives.

On the other hand, after the announcement of the participants to repeat the violent scene and continue to observe and learn from it, we can say that what the adolescents have learned will increase their susceptibility to violent scenes. Adolescents will encode the information they receive and transform it into real activities. In the case of receiving rewards and reinforcement, they will have a firmer motivation to engage in violent behavior. As a result of repeated violent and aggressive behavior, their decision-making would not be logical and rational and would lead to risky decisions.

The other finding of the current study showed that watching melodrama movies did not significantly increase adolescents' decision-making. The research of Forgas and East (2008) did not confirm the above result. The result of their study showed that watching melodrama movies has a positive influence on risky decision-making. The subjects of this study watched both comedy and melodrama movies for 10 minutes. The results showed that the comedy movie leads to faster and more rational decision-making, while the melodrama movie leads to delayed and riskier decision-making. The difference between the above results and the results of this study may be due to the difference in the cultural context of the subjects. Based on social learning theory, internal and external rewards and reinforcement motivate a person to act. As adolescents welcome violent media products, other media works are produced that do not contain violent content and encourage and reward emotional and kind behaviors. Another reason is that today's youth are less willing to watch melodramas and emotional works. However, the production of melodramas on TV and even home movies are decreasing.

Another finding of the present study was that watching violence in movies leads to a weakening in behavioral inhibition of the participants. The research find- ings of Alia-Klein et al. (2014) confirmed this finding. Based on this result, watching media violence will affect the inhibition power of people and weakens it. This finding also suggests that watching media violence will increase the delay in responding to the subject. Since we have explained that violence affects the executive function of the brain, we can conclude that learning violence, whether in the natural environment, such as home or school, or the simulated environment, such as in media content, could weaken the inhibition power in people, especially adolescents, and suppress the stopping or delaying of unwanted and unnecessary activities. Aggressive behavior is the inability of adolescents to respond appropriately to environmental stimuli. According to the Berkowitz stimulus effect theory, violent thoughts, analyses, and even behaviors in people are stimulated by watching aggressive behaviors on TV, especially in movies. This finding converts people's logical and winning thinking, behavior, and analysis into inappropriate thinking and behavior (Zulfiqar, 2020). This issue is especially real for adolescents with weaker diagnostic abilities who cannot analyze whether it is correct to respond to environmental stimuli by imitating violent TV shows.

Another finding of the present study suggests that watching melodrama movies does not significantly weaken adolescents' behavioral inhibition. Reading dramas, including the works of Shakespeare, resulted in positive brain performance. They found that when subjects were exposed to reading works of melodrama, their emotions were more positive and the cognitive function of their brains improved. Among the brain's cognitive functions that were assessed in this study, one can mention memory and problem-solving.

This study also showed that watching violent movies increased blood pressure significantly (systolic and diastolic). Also, Denson et al. (2020) suggested that watching a movie with violent content increases the systolic and diastolic blood pressure of the subjects. Playing violent computer games increases systolic and diastolic blood pressure in adolescents compared to non-violent computer games. To explain this finding, it can be said that watching violence directly affects arousal and thus increases arousal in people (Verheijen, et al., 2021). According to Koepp et al. (1998) watching violence in movies releases dopamine and increases arousal and stress. Based on Tannenbaum's stimulation theory, exposure to violent media will increase aggressive behavior because it will increase fear and anxiety and thus stimulate or arousal the viewer. 
Another finding of this study suggests that watching melodrama movies increases blood pressure (systolic and diastolic) in adolescents. Since there is no research on the effect of watching a melodrama movie on vital signs, we will refer to another study that indirectly indicates the effect or lack of effect of watching a melodrama movie on vital signs. Sanchez-Ruiz, et al. (2019) reported that watching melodrama movies does not increase stress and anxiety (associated with increased physiological arousal). Siervo, et al. (2013) concluded that playing non-violent computer games has no significant effect on systolic and diastolic blood pressure. Another finding of the present study was that watching violent movies increases heart rate in adolescents. Playing violent computer games significantly affects heart rate and increases heart rate.

The final result of the present study suggests that watching melodrama movies did not increase the heart rate of adolescents. Hummer et al. (2014) indicated that watching melodrama movies did not increase stress and anxiety (associated with increased physiological arousal). Playing non-violent computer games has no significant effect on heart rate. In explaining the findings regarding physiological symptoms, it can be concluded that what stimulates people's emotions would alter individuals' vital signs. Thus, watching violent or emotional stories that lead to daydreaming and fantasies in adolescents could cause some changes due to the increase or decrease in vital signs. Therefore, watching violent or melodrama movies could equally affect the arousal of adolescents and increase their stress levels (Dill \& Dill, 1998; Greitemeyer, 2018).

According to these findings, it can be assumed that movies with violent content and a story that exerts violence on people and especially adolescents, negatively affect their decision-making and inhibition power, pushing them to make risky decisions. The production of movies or media works in general, in which violence is presented as the main theme and is promoted by the selection of famous, well-known, good-looking, and well-dressed actors, leads children and adolescents to learn violent behavior and practice violent behavior in their real lives. According to the results of this research, watching violence accompanied by violent behavior and language affects the decisionmaking and inhibition power of adolescents. If children and adolescents watch such works repeatedly and persistently, we will see that the viewer cannot make a rational decision and inhibit his irrational behavior; both in adolescence and adulthood, the risky decisions and the inability to inhibit inappropriate behavior will increase in them.

The effects of risky decisions and lack of inhibition are reflected in personal life and have unpleasant consequences in social life. These reckless decisions and inability to choose the right path may affect the person in, for example, choosing a field of study, a friend, a job, or a spouse, and confront him or her with the negative consequences of wrong choices or they may lead to more serious social harms such as theft, addiction, murder, and suicide.

\section{Ethical Considerations}

\section{Compliance with ethical guidelines}

Since showing violent films to adolescents was considered in conducting this study, participants were asked to give their consent. In return, the researcher agrees to keep the participants' personal information confidential and use it only for this study. Before conducting the research, the consent form was also filled out by the subjects' parents. The subjects who watched the violent movie were also given anger control training after watching the movie and taking the tests. This training includes taking deep breaths, pausing, visualizing a relaxing image, repeating a relaxing word or phrase, or drinking a glass of water. All research processes involving people followed the ethical values of the National Research Committee, the 1964 Helsinki Declaration, subsequent amendments, or appropriate ethical standards. All participants signed an informed consent form when returning the survey, and the scales were completed anonymously. The authors declare that they have no competing interests.

\section{Funding}

This research did not receive any grant from funding agencies in the public, commercial, or non-profit sectors.

\section{Authors' contributions}

All authors equally contributed to preparing this article.

\section{Conflict of interest}

The authors declare no conflict of interest. 


\section{References}

Alia-Klein, N., Wang, G. J., Preston-Campbell, R. N., Moeller, S. J., Parvaz, M. A., \& Zhu, W., et al. (2014). Reactions to media violence: It's In the brain of the beholder. Plos One, 9(9), e107260. [DOI:10.1371/journal.pone.0107260] [PMID] [PMCID]

Anderson, C. A., Suzuki, K., Swing, E. L., Groves, C. L., Gentile, D. A., \& Prot, S., et al. (2017). Media violence and other aggression risk factors in seven nations. Personality and Social Psychology Bulletin, 43(7), 986-998. [PMID]

Chang, J. H., \& Bushman, B. J. (2019). Effect of exposure to gun violence in video gamechildren's dangerous behavior with real guns: A randomized clinical trial. JAMA Network Open, 2(5), e194319. [PMID] [PMCID]

Coyne, S. M., Stockdale, L., Linder, J. R., Nelson, D. A., Collier, K. M., \& Essig, L. W. (2017). Pow! Boom! Kablam! effects of viewing superhero programs on aggressive, prosocial, and defending behaviors in preschool children. Journal of Abnormal Child Psychology, 45(8), 1523-1535. [DOI:10.1007/ s10802-016-0253-6] [PMID]

Darjee, R. (2019). Sexual sadism and psychopathy in sexual homicide offenders: An exploration of their associates in a clinical sample. International Journal of Offender Therapy and Comparative Criminology, 63(9), 1738-1765. [DOI:10.1177/0306624X19836872] [PMID]

Denson, T. F., Dixson, B. J. W., Tibubos, A. N., Zhang, E., Harmon-Jones, E., \& Kasumovic, M. M. (2020). Violent video game play, gender, and trait aggression influence subjective fighting ability, perceptionmen's toughness, and anger facial recognition. Computers in Human Behavior, 104, 106175. [DOI:10.1016/j.chb.2019.106175]

Dill, K. E., \& Dill, J. C. (1998). Video game violence: A review of the empirical literature. Aggression and Violent Behavior 3(4), 407-428. [DOI:10.1016/S1359-1789(97)00001-3]

Ekhtiari, H., Victor, T. A., \& Paulus, M. P. (2017). Aberrant decision-making and drug addiction-How strong is the evidence? Current Opinion in Behavioral Sciences, 13, 25-33. [DOI:10.1016/j.cobeha.2016.09.002]

Fernie, G., \& Tunney, R. J. (2006). Some decks are better than others: The effect of reinforcer type and task instructions on learning in the Iowa Gambling Task. Brain and Cognition, 60(1), 94-102. [DOI:10.1016/j.bandc.2005.09.011] [PMID]

Fikkers, K. M., Piotrowski, J. T., \& Valkenburg, P. M. (2017). A matter of style? Exploring the effects of parental mediation styles on eadolescents' media violence exposure and aggression. Computers in Human Behavior, 70, 407-415. [DOI:10.1016/j.chb.2017.01.029]

Forgas, J. P., \& East, R. (2008). On being happy and gullible: Mood effects on skepticism and the detection of deception. Journal of Experimental Social Psychology, 44(5), 1362-1367. [DOI:10.1016/j.jesp.2008.04.010]

Greitemeyer, T. (2018). The spreading impact of playing violent video games on aggression. Computers in Human Behavior, 80, 216-219. [DOI:10.1016/j.chb.2017.11.022]

Hopf, W. H., Huber, G. L., \& Weiß, R. H. (2008). Media violence and youth violence: A 2-year longitudinal study. Journal of Media Psychology, 20(3), 79-96. [DOI:10.1027/18641105.20.3.79]
Hosseini, S. H., Zarghami, M., Moudi, S., \& Mohammadpour, A. R. (2012). Frequency and severity of obsessive-compulsive symptoms/disorders, violence and suicidal in schizophrenic patients. Iranian Red Crescent Medical Journal, 14(6), 345-351. [Link]

Hu, B. Y., Johnson, G. K., Teo, T., \& Wu, Z. (2020). Relationship Between Screen Time and ChiChildren's Cognitive and Social Development. Journal of Research in Childhood Education 34(2), 183-207. [DOI:10.1080/02568543.2019.1702600]

Hummer, T. A., Kronenberger, W. G., Wang, Y., Anderson, C. C., \& Mathews, V. P. (2014). Association of television violence exposure with executive functioning and white matter volume in young adult males. Brain and Cognition, 88 26-34. [DOI:10.1016/j.bandc.2014.04.010] [PMID]

Khurana, A., Bleakley, A., Ellithorpe, M. E., Hennessy, M., Jamieson, P. E., \& Weitz, I. (2019). Media violence exposure and aggression in adolescents: A risk and resilience perspective. Aggressive Behavior, 45(1), 70-81. [DOI:10.1002/ ab.21798] [PMID]

Koepp, M. J., Gunn, R. N., Lawrence, A. D., Cunningham, V. J., Dagher, A., \& Jones, T., et al. (1998). Evidence for striatal dopamine release during a video game. Nature, 393(6682), 266-268. [DOI:10.1038/30498] [PMID]

Kronenberger, W. G., Mathews, V. P., Dunn, D. W., Wang, Y., Wood, E. A., Giauque, A. L., et al. (2005). Media violence exposure and executive functioning in aggressive and control adolescents. Journal of Clinical Psychology, 61(6), 725-737. [Link]

Li, J., Du, Q., \& Gao, X. (2020). Adolescent aggression and violent video games: The role of moral disengagement and parental rearing patterns. Children and Youth Services Review, 118, 105370. [DOI:10.1016/j.childyouth.2020.105370]

Lillard, A. S., Li, H., \& Boguszewski, K. (2015). Televisionchildren's executive function. Advances in Child Development and Behavior, 48, 219-248. [DOI:10.1016/bs.acdb.2014.11.006] [PMID]

Liu, Q., Huang, J., \& Zhou, Z. (2020). Self-expansion via smartphone and smartphone addiction tendency among adolescents: A moderated mediation model. Children and Youth Services Review, 119, 105590. [DOI:10.1016/j.childyouth.2020.105590]

Mueller, E. M., Nguyen, J., Ray, W. J., \& Borkovec, T. D. (2010). Future-oriented decision-making in Generalized Anxiety Disorder is evident across different versions of the Iowa Gambling Task. Journal of Behavior Therapy and Experimental Psychiatry, 41(2), 165-171. [PMID]

Peters, W., Rice, S., Cohen, J., Murray, L., Schley, C., \& Alvarez-Jimenez, M., et al. (2021). Trauma-focused cognitivebehavioral therapy (TF-CBT) for interpersonal trauma in transitional-aged youth. Psychological Trauma: Theory, Re search, Practice, and Policy, 13(3), 313-321. [PMID]

Rostad, W. L., Basile, K. C., \& Clayton, H. B. (2021). Association among television and computer/video game use, victimization, and suicide risk among U.S. high school students. Journal of Interpersonal Violence, 36(5-6), 2282-2305. [DOI:10.1177/0886260518760020] [PMID] [PMCID]

Sanchez-Ruiz, M. J., El-Jor, C., Abi Kharma, J., Bassil, M., \& Zeeni, N. (2019). Personality, emotion-related variables, and media pressure predict eating disorders via disordered eating in Lebanese university students. Eating and Weight Disorders : EWD, 24(2), 313-322. [DOI:10.1007/s40519-017-0387-8] [PMID] 
Seabrook, R. C., Ward, L. M., \& Giaccardi, S. (2019). Less than human? Media use, objectification of women,men's acceptance of sexual aggression. Psychology of Violence, 9(5), 536545. [DOI:10.1037/vio0000198]

Siervo, M., Sabatini, S., Fewtrell, M. S., \& Wells, J. C. (2013). Acute effects of violent video-game playing on blood pressure and appetite perception in normal-weight young men: A randomized controlled trial. European Journal of Clinical Nutrition, 67(12), 1322-1324. [DOI:10.1038/ejcn.2013.180] [PMID]

Sumner, S. A., Mercy, J. A., Dahlberg, L. L., Hillis, S. D., Klevens, J., \& Houry, D. (2015). Violence in the United States: Status, challenges, and opportunities. JAMA, 314(5), 478488. [PMID] [PMCID]

Tabibi, Z., Borzabadi, H. H., Stavrinos, D., \& Mashhadi, A. (2015). Predicting aberrant driving behaviour: The role of executive function. Transportation Research Part F: Traffic Psychology and Behaviour, 34, 18-28. [DOI:10.1016/j. trf.2015.07.015]

Van Bavel, B., Ansink, E., \& Van Besouw, B. (2017). Understanding the economics of limited access orders: Incentives, organizations and the chronology of developments. Journal of Institutional Economics, 13(1), 109-131. [DOI:10.1017/ S1744137416000254]

Verheijen, G. P., Burk, W. J., Stoltz, S. E. M. J., van den Berg, Y. H. M., \& Cillessen, A. H. N. (2021). A longitudinal social network perspective on adolescents' exposure to violent video games and aggression. Cyberpsychology, Behavior, and Social Networking, 24(1), 24-31. [PMID]

Weegels, J. (2018). The terror and scourge of barrio: Representations of youth crime and policing on nicaraguan television news. Journal of Latin American Studies, 50(4), 861-887. [DOI:10.1017/S0022216X18000317]

Zhuang, X., Lau, Y. Y., Huang, Y. T., Tam, C. H. L., Chan, W. M. H., \& Yeung, K. K. W., et al. (2021). Efficacy of lowintensity cognitive behavior intervention for Chinese delinquent youth. Research on Social Work Practice, 32(2), 155-167. [DOI:10.1177/10497315211013897]

Zulfiqar, S. H. (2020). Does media violence cause violence? can exposure to violent tv shows, movies and video games turn people aggressive and desensitized to violence? SSRN Electronic Journal, 1-29. [Link] 
This Page Intentionally Left Blank 